\title{
Prevalence of Atrial Fibrillation in Systolic Heart Failure, Pulsed and Tissue Doppler Echocardiographic Abnormalities
}

\author{
Salih H. Gabani ${ }^{1}$, Taysir S. Garadah ${ }^{1,2 *}$, Adela B. Hassan ${ }^{1}$, Ahmed A. Jaradat ${ }^{1}$, \\ Mohamed E. Al Alawi ${ }^{1,2}$, Zuheir A. Hasan ${ }^{1}$ \\ ${ }^{1}$ College of Medicine and Medical Sciences, Arabian Gulf University, Manama, Kingdom of Bahrain; ${ }^{2}$ Salmaniya Medical Complex, \\ Ministry of Health, Manama, Kingdom of Bahrain. \\ Email: "garadaht@hotmail.com
}

Received September $28^{\text {th }}, 2013$; revised October $25^{\text {th }}, 2013$; accepted November $2^{\text {nd }}, 2013$

Copyright (C) 2013 Salih Gabani et al. This is an open access article distributed under the Creative Commons Attribution License, which permits unrestricted use, distribution, and reproduction in any medium, provided the original work is properly cited.

\begin{abstract}
Background: Heart failure (HF) is a common clinical syndrome mostly due to the impaired ability of the Left Ventricle (LV) to eject blood with reduced cardiac output. Heart failure is called systolic (SHF) if left ventricle ejection fraction on echo-cardiogram is low (LVEF of $\leq 50 \%$ ). Aim: To assess the echocardiographic characteristics of patients with SHF with Atrial Fibrillation (AF) and compare with those with Sinus Rhythm (SR) on 12 leads ECG. Furthermore, to evaluate the clinical and biochemical markers for the prediction of AF in SHF. Method: Over two years duration, each patient diagnosed with SHF was enrolled in the study $(n=354)$ based on admission code. AF or sinus rhythm on 12 leads ECG was documented on each patient. Multiple logistic regression analysis was applied to assess the risk ratio of different clinical and Doppler derived variables for the development of AF in SHF. Results: Out of the total hospital medical admissions of 14,674 patients, there were 354 patients with diagnosis of SHF, a prevalence of $2.4 \%$. The incidence of AF on ECG was 109 (31\%) patients in the whole study population and $245(69 \%)$ in SR. M Mode echocardiogram in patients with SHF and AF compared with those in SR showed significant dilation of LV cavity in systole with LVESD of $5.72 \pm 0.63$ vs. $5.23 \pm 0.76 \mathrm{~cm}, \mathrm{P}<0.001$ and in Diastole LVEDD of $6.83 \pm 0.51$ vs. $6.58 \pm$ $0.63 \mathrm{~cm}, \mathrm{P}<0.001$. Pulsed Doppler echocardiogram showed a severe restrictive-pattern with shorter Decellration Time (DT) of $163.73 \pm 7.42$ vs. $214.9 \pm 31.81 \mathrm{msec}, \mathrm{P}<0.001$ and higher Pulse to Tissue Doppler ratio of E/Em of $14.26 \pm$ 1.34 vs. $9.99 \pm 1.27, \mathrm{P}<0.001$, and the serum level of Brain Natriuretic Peptide (BNP) hormone of $723.72 \pm 13.45$ vs. $686.98 \pm 72.57 \mathrm{pg} / \mathrm{ml}, \mathrm{P}<0.001$. The predictive risks (odd ratio) of different clinical variables for the development of $\mathrm{AF}$ in SHF were positive for high BNP $>500 \mathrm{pg} / \mathrm{ml}$ of 2.8 , history of hypertension of 1.8 , history of DM of 1.7 , BMI $>$ 28 of 1.4, LV hypertrophy on ECG of 1.3. Conclusions: The prevalence of Systolic Heart Failure in the study population was $2.4 \%$. The prevalence of AF in the study population was $31 \%$. The best predictors of AF in SHF were high BNP $>500 \mathrm{pg} / \mathrm{ml}$, history of hypertension, Diabete Mellitus and LV Hypertrophy on ECG.
\end{abstract}

Keywords: Systolic Heart Failure; Pulse Doppler; Tissue Doppler; Prevalence

\section{Introduction}

Heart failure (HF) is a common clinical syndrome representing the end-stage of a number of different cardiac diseases [1]. It can result in any structural or functional cardiac disorder that impairs the ability of the ventricle to fill with or eject blood [2]. There are two mechanisms by which reduced cardiac output and HF occur: Systolic Heart Failure (SHF) with low left ventricle ejection frac-

${ }^{*}$ Corresponding author. tion on echocardiogram (LVEF of $\leq 50 \%$ ) and diastolic heart failure (DHF) with normal LVEF of $>50 \%$ [3].

SHF has been classified as very mild, mild, moderate or severe based on echocardiographic derived LVEF\% where very mild LVEF\% is $(<43 \%-\geq 50 \%)$, mild (LVEF of $<33 \%-\geq 43 \%)$, moderate $(<23 \%-\geq 33 \%)$ and severe with LVEF $(<22 \%)$ [4]. Systolic Heart Failure has been recognized previously as a risk factor for the development of Atrial Fibrillation (AF) [5]. The overall prevalence of new onset of $\mathrm{AF}$ in hospitalized patients with 
SHF is in the range of $8 \%-36 \%$ [6]. It has been observed that the incidence of $\mathrm{AF}$ is proportional to the severity of HF where a higher incidence occurs in severe SHF [7].

Previous reports showed a deleterious impact of AF on top of SHF with poor clinical outcomes in terms of mortality and hospitalization [8,9]. Randomized pathophysiologic studies showed important differences between patients presented with SHF as compared with those of DHF as it seems that the two conditions represent two distinct syndromes rather than a continuous spectrum of one disorder $[10,11]$.

Earlier reports showed the high sensitivity of brain natriuretic peptide (BNP) as a biomarker of detecting a symptomatic SHF with low LVEF on echo of $<50 \%$ [12]. Further, a serum level of BNP was shown to have prognostic implications in patients with SHF [13]. At present, the relationship between SHF and the development of AF in non white population is not clear.

In this study, firstly, we assess the incidence of $\mathrm{AF}$ in patients with SHF; secondly, evaluate the clinical characteristics, causative agents and echocardiographic abnormalities in this group of patients and thirdly, correlate the serum level of BNP with the degree of LVEF\% reduction on echo.

\section{Material and Methods}

Out of the 14,674 patients admitted to the Salmaniya Medical Complex (SMC) in the medical department with acute medical problems. There were 354 patients diagnosed of systolic heart failure. SMC is a governmental hospital with a catchment area of 900,000 populations. All patients' data of clinical history, physical examination, and laboratory results were obtained. The results of echocardiogram and 12 leads electrocardiogram were available for all patients on admission or during hospital stay. The clinical and biochemical data were extracted from patient's files. The study duration for medical admission was of two years, spanning from 1 January 2010 - 31 December 2011. A constitutional ethical committee approval was obtained prior to the data extraction and analysis.

The history of SHF class was obtained based on New York Heart Associations (NYHA) functional classification [14]. The clinical findings on examination of third sound gallop, pulmonary crackles, and raised jugular venous pressure, hepatomegaly and ankle edema were all recorded. Height and weight, goiter, murmur suggestive of aortic or mitral or pulmonary valve disease were all recorded. Demographic data for previous attacks of heart failure, hypertension and diabetes mellitus (DM) prior to admission were all recorded. History of smoking and previous history for the development of AF were extracted from the patients' files. Twelve leads ECG was analyzed for voltage criteria of left ventricle hypertrophy using Perugia score [15].

Atrial fibrillation was defined as absence of $\mathrm{P}$ wave on 12 leads electrocardiogram (ECG), with irregular ventricular rhythm that lasting for $>30$ seconds [16]. The presence of Q wave and conduction abnormality with ST segment elevation or depression or $\mathrm{T}$ wave changes were all recorded. Echocardiographic data of the M mode, 2-D echo, Pulsed and Tissue Doppler were all tabulated regarding the M mode of LV cavity dimensions and LV wall thickness. The calculated LV mass index, indices of left ventricle diastolic fillings such as deceleration time (DT) in msec, E wave velocity in early diastole in $\mathrm{cm} /$ sand the ratio of early diastolic pulsed to Tissue Doppler wave $(\mathrm{E} / \mathrm{Em})$ were recorded [17].

Based on LVEF\% using two dimension echo formula [18], patients were defined as those SHF with reduced (LVREF\%) of $\leq 50 \%$ and DHF with preserved (LVPEF\%). Further,those SHF patients were subgrouped as very mild SHF ( $L V R E F \%<43-\geq 50 \%$ ), mild (LVREF of $<33-\geq 43 \%)$, moderate $(<23-\geq 33 \%)$ and severe $(<22 \%)[19,20]$.

The diastolic dysfunction of LV was regarded as severe if deceleration time (DT) of E wave was $<160 \mathrm{msec}$ and the early E Pulsed wave to Tissue Doppler wave (E/Em ratio) was $>12$ [21]. The estimated LV mass index on echo of $>131 \mathrm{~g} / \mathrm{m} 2$ for men and $>113 \mathrm{~g} / \mathrm{m}^{2}$ for women was defined as cut off points for severe LVH [22].

The results of available serum level of brain natriuretic peptide (BNP), uric acid, estimated glomerular filtration rate (eGFR) and serum potassium were tabulated.

\section{Statistical Analysis}

The data were analyzed using the statistical package of social sciences (SPSS) version 20. All data were presented as mean $\pm \mathrm{SD}$. Student's t-test was used to test the differences between the mean variables of $\mathrm{M}$ mode for septal wall thickness, LV cavity and LV mass index in the two groups of heart failure and Chi-square analysis was used to test the differences between proportions of categorical variables.

Multiple logistic regression analysis was applied to calculate the odds ratio for different clinical and biochemical variables for the development of $\mathrm{AF}$ in patients with SHF. All reported p-values are two tailed and pvalue was regarded as significant at level of $<0.05$.

\section{Results}

Three hundred and fifty four patients with clinical diagnosis of systolic heart failure were enrolled. There were 354 defined as SHF with LVEF $<50 \%$ on echocardiogram. Among the 354 patients with SHF, 12 leads ECG showed AF in 109 (31\%) patients and 245(69\%) were in 
sinus rhythm (SR).

The mean age of patients in the study was $60.47 \pm$ 11.43 years. There were $191(54.0 \%)$ female patients. There were $30(8.5 \%)$ patients with history of hypertension, $60(16.9 \%)$ with history of smoking, BMI was $>28$ in $35(9.9 \%)$, history of hyperlipidemia was in 53 $(15.0 \%)$, patients, DM in $56(15.8 \%)$ and history of myocardial ischemia in $40 \%(11.2 \%)$.

\section{ECG}

In the whole study, there were 109 (31\%) who had AF on admission and sinus rhythm was seen in $245(69 \%)$.

Among those who had AF $(\mathrm{n}=109)$ on 12 leads ECG there were $34(31 \%)$ patients with no history or documents of previous $\mathrm{AF}$ and they were regarded as new onset of AF, $26(24 \%)$ patients had history of persistent $\mathrm{AF}$ and $49(45 \%)$ patients had history of recurrent or paroxysmal AF.

Patients with left ventricle hypertrophy based on ECG criteria were 73 out of 354 (20.6\%). Among those with LVH there were $(25.5 \%)$ patients with $\mathrm{AF}$ and $(74.5 \%)$ were in sinus rhythm. The overall sensitivity and specificity of ECG for detection of LVH compared with LV mass index derived by echo as gold standard was $79 \%$ and $63 \%$ respectively.

\section{Clinical Findings}

There were $141(40 \%)$ patients with left ventricle failure manifested with pulmonary odema, $123(35 \%)$ patients had both left ventricular and right ventricular failure (biventricular) and $88(25 \%)$ had right sided heart failure.

The history of functional (NYHA) class on admission was as follow: $70(20 \%)$ patients had functional class IV, $130(37 \%)$ had class III, 152 (43\%) patients had functional class II and none had class I.

\section{Medication Prior to Admission}

There were 336 (94.9\%) patients using angiotensinconverting enzyme blocker (ACE) medication, 239 $(67.5 \%)$ were on diuretics, $127(35.9 \%)$ on beta blocker, and $56(16.9 \%)$ were on digoxin medication.

\section{Systolic Heart Failure and Patient's Age}

Figure 1 shows the age distribution in patients with SHF. There were 95 (26.8) patients in the young age category of $<50$ years, $114(40.6 \%)$, in age category of between 50 - 65 year and $115(32.4 \%)$ patients in age category of $>65$ year.

\section{Echocardiographic and Biochemical Variables}

Table 1 shows biochemical, M mode, pulsed and tissue

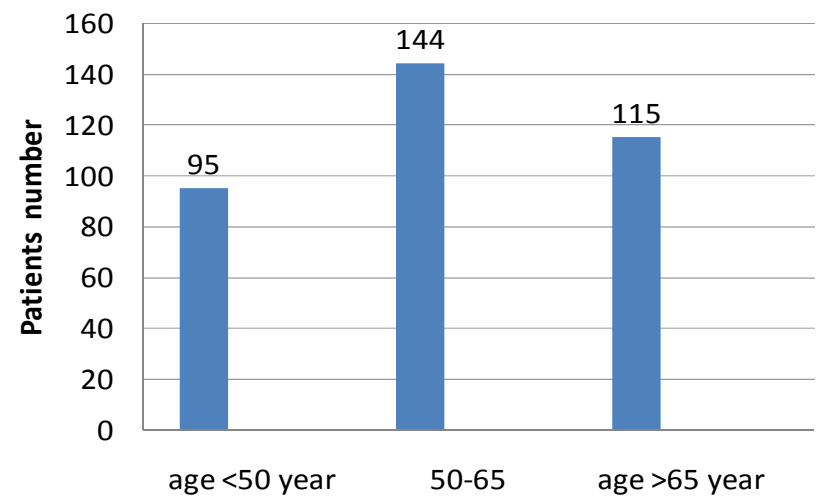

Figure 1. Distribution of patients according to age in patient with systolic heart failure, $n=354$.

Table 1. The mean value standard deviation (SD) of Biochemical markers and echocardiographic indices in all patients presented with $\mathrm{SHF}, \mathrm{N}=354$.

\begin{tabular}{cccc}
\hline ECG & AF & SR & P value \\
& $\mathrm{N}=109$ & $\mathrm{~N}=245$ & \\
\hline IVS cm & $0.98 \pm 0.22$ & $0.97 \pm 0.94$ & 0.083 \\
PW cm & $0.89 \pm 0.12$ & $0.88 \pm 0.12$ & 0.071 \\
ESD cm & $5.72 \pm 0.63$ & $5.23 \pm 0.76$ & 0.001 \\
EDD cm & $6.83 \pm 0.51$ & $6.58 \pm 0.63$ & 0.001 \\
LV Mass Index & $111.58 \pm 2.81$ & $112.20 \pm 3.05$ & 0.063 \\
DT msc & $163.73 \pm 7.42$ & $214.90 \pm 31.81$ & 0.001 \\
E/Em ratio & $14.26 \pm 1.34$ & $9.99 \pm 1.27$ & 0.001 \\
BNP in (pg/ml) & $723.72 \pm 13.45$ & $686.98 \pm 72.57$ & 0.001 \\
Uric acid (mmol/L) & $472.25 \pm 34.14$ & $397.62 \pm 92.08$ & 0.001 \\
eGFR & $56.21 \pm 12.59$ & $76.65 \pm 10.57$ & 0.001 \\
Potassium (mmol/L) & $3.43 \pm 0.27$ & $3.78 \pm 0.24$ & 0.001 \\
\hline
\end{tabular}

Abbreviations: SHF: Systolic heart failure; IVS Interventricular septum PW: posterior wall; ESD: end systolic Dimension; EDD: end diastolic dimension; DT: Deceleration time; eGFR: estimated glomerular filtration rate; AF: Atrial fibrillation; SR: Sinus rhythm; E/Em: ratio of E velocity to Tissue Doppler velocity of septum; BNP: Brain Natriuretic Peptide.

Doppler echocardiogram results in patients with SHF.

In patients with SHF and AF compared with SR on 12 leads ECG. Echocardiographic $M$ mode measurement showed no significant difference in LV wall thickness or $\mathrm{LV}$ mass index of $\mathrm{P}=0.083$ and $\mathrm{P}=0.063$ respectively. However LV cavity showed significant dilation in both systole and diastole. Pulse and tissue Doppler showed significantly shorter DT of $\mathrm{E}$ wave of $163.7 \pm 7.4$ vs. $214.9 \pm 31 \mathrm{msec}, \mathrm{P}<0.001$, higher $\mathrm{E} / \mathrm{Em}$ ratio of $14.26 \pm$ 1.34 vs. $9.99 .1 \pm 1.27, \mathrm{P}<0.05$.

\section{Biochemical Markers}

In SHF patients with AF compared with those in SR, there was significantly higher level of uric acid, BNP level but a lower eGFR and low serum potassium. Furthermore, Two D segmental wall motion abnormallities suggesting ischemia were detected in $38(11.9 \%)$ in pa- 
tients with $\mathrm{AF}$ patients versus $22(6.7 \%)$ in those with SR.

\section{Etiological Diagnosis}

In patients with SHF $(n=354)$ there were $113(31.9 \%)$ patients with dilated cardiomyopathy with global hypokinesia, $31(8.7 \%)$ had hypertension heart failure, 74 $(20.9 \%)$ had ischemic heart disease with old myocardial infarction in 36(10.1\%) patients, 67 (18.9\%) had significant valve disease with $28(7.9 \%)$ of severe mitral valve regurgitation and $18(5.0 \%)$ had severe aortic regurgitation, 17 (4.8\%) patients had thyroid disease and 35 (9.9\%) were of unknown etiology.

\section{The Odds Ratio for Risk of AF in SHF Patients}

Table 2 shows the hazard ratio of clinical and biochemical variables in the study for the developing of $\mathrm{AF}$ in patients with SHF. After adjusting for age and sex multiple logistic regression analysis showed positive predictive value for: history of hypertension of 1.8 , history of DM of 1.7, for BMI $>28$ of 1.4, LVH on ECG of 2.4.

The positive predictors biomarker were hyperuricemia $>420 \mathrm{mmol} / \mathrm{l}$ of 2.1 higher $\mathrm{BNP}>500 \mathrm{pg} / \mathrm{ml}$ of 2.8 and low estimated glomerular filtration rate (eGFR) $<50$ of $2.1, \mathrm{LVH}$ of 1.3 and hypokalemia of $<3.4 \mathrm{mmol} / 1$ of 1.2 .

\section{Discussion}

Patients with heart failure in this study were evaluated with echocardiogram and ECG for the development of AF. Patients who had systolic heart failure on echo had reduced $\mathrm{EF} \leq 50 \%$. SHF patients had high female distribution and mostly age of between $50-65$ years. This finding is in keeping with previous report, where $49 \%$ of patients with systolic heart failure were below the age of 70 year [10].

The overall prevalence of systolic heart failure in the

Table 2. The hazard ratio for the development of AF in patients presented with systolic heart failure using multiple logistic regression analysis in patients presented with systolic heart failure, $n=354$.

\begin{tabular}{cccc}
\hline Variable & Odds ratio & $\begin{array}{c}\text { 95\% Confidence } \\
\text { interval }\end{array}$ & P value \\
\hline History of hypertension & 1.8 & $(1.2-2.4)$ & 0.036 \\
History of DM & 1.7 & $(1.2-2.2)$ & 0.037 \\
BMI $>28$ & 1.4 & $(0.9-1.9)$ & 0.028 \\
LV hypertrophy on ECG & 1.3 & $(1.0-1.6)$ & 0.021 \\
K $<3.4 \mathrm{mmol} / \mathrm{L}$ & 1.2 & $(0.9-1.5)$ & 0.043 \\
Uric acid $>420 \mathrm{mmol} / \mathrm{L}$ & 2.1 & $(1.7-2.4)$ & 0.021 \\
eGFR $<50$ & 2.1 & $(1.5-2.8)$ & 0.013 \\
BNP $>500 \mathrm{pg} / \mathrm{ml}=\mathrm{pg} / \mathrm{L}$ & 2.8 & $(2.1-3.5)$ & 0.001 \\
\hline
\end{tabular}

Abbreviations: BNP: Brain Natriuretic Peptide; eGFR: estimated Glomerular Filtration Rate; K: Potassium; BMS: Body Mass Index. study in two years was $2.4 \%$. This was lower than other studies with prevalence of $4.1 \%$ and 4.2 respectively $[23,24]$. The prevalence in of SHF was $2.4 \%$ is similar to one study by Mureddu GF et al. [25].

The rate of occurrence of AF patients with $\mathrm{HF}$ in whole the study was of $31 \%$ which was higher than previous report found in occurrence of $25 \%$ [26].

In different clinical trials, the use of different diagnostic criteria and different age groups leads to variation of prevalence of HF. In one study by Grewal J, et al., the prevalence of HF was $1.9 \%$ [27] and in another study by Phillips SJ et al., [28] as the prevalence of HF was of $1.7 \%$. In both studies the prevalence was lower compared with this study although the prevalence was increasing as the patient's age increased.

In this study the percentage of female gender was high in SHF. In previous studies female gender in SHF accounting to $25 \%-35 \%$ of systolic heart failure [29]. In another report male gender had doubled the risk of developing blood-pumping problems (SHF) compared with female [30].

The age distribution in SHF showed increment in the rate of SHF mostly between 50 and 65 year. In one study the estimated prevalence of systolic dysfunction among patients was different where $15 \%$, were at ages $<50$ year, $33 \%$ at age of $50-70$ year, and $50 \%>70$ years, [31]. In one report, a higher incidence of SHF was observed in patients aged $<65$ years due to ischemia and hypertension [32].

The level of BNP was significantly higher in SHF with AF. This finding had been shown previously, where BNP was significantly high in dilated SHF [27]. In one report higher level of BNP $>100 \mathrm{pg} / \mathrm{ml}$ was shown as an independent predictor of adverse cardiovascular outcome in patients with DHF [33].

The serum level of potassium in AF patients in patients with SHF was lower than those with Sinus rhythm. Previous studies showed the incidence of AF compared with SR is inversely related with level of serum Potassium [34].

In this study a higher rate of segmental wall motion abnormality on echo was detected in patients with AF. The causative agents of SHF were mainly idiopathic dilated myopathy followed by valvular heart disease. In one report by Topol et al., hypertension and ischemia were the main etiology of DHF [35].

Patients in SHF with dilation of LV on echo, tachycardia-mediated cardiomyopathy were presumed to be the causative agent in $29 \%$ of patients with HF however. In this subset of patients improvement of LV function is expected to improve as patient revert to sinus rhythm $[36,37]$.

\section{Conclusion}

The prevalence of SHF was $2.4 \%$ in the study population, 
with the incidence of AF being $31 \%$ in the whole study. The best predictors of AF in HF were high BNP $>500$ $\mathrm{pg} / \mathrm{ml}$, left ventricle hypertrophy on ECG followed by history of hypertension and DM.

\section{REFERENCES}

[1] V. L. Roger, "The Heart Failure Epidemic," International Journal of Environmental Research and Public Health, Vol. 7, No. 4, 2010, pp. 1807-1830. http://dx.doi.org/10.3390/ijerph7041807

[2] S. A. Hunt, W. T. Abraham, M. H. Chin, et al., "2009 Focused Update Incorporated into the ACC/AHA 2005 Guidelines for the Diagnosis and Management of Heart Failure in Adults: A Report of the American College of Cardiology Foundation/American Heart Association Task Force on Practice Guidelines: Developed in Collaboration with the International Society for Heart and Lung Transplantation," Circulation, Vol. 119, No. 14, 2009, pp. e391-479.

http://dx.doi.org/10.1161/CIRCULATIONAHA.109.1920 $\underline{65}$

[3] K. Dickstein, A. Cohen-Solal, G. Filippatos, et al., "ESC Guidelines for the Diagnosis and Treatment of Acute and Chronic Heart Failure 2008: The Task Force for the Diagnosis and Treatment of Acute and Chronic Heart Failure 2008 of the European Society of Cardiology. Developed in collaboration with the Heart Failure Association of the ESC (HFA) and Endorsed by the European Society of Intensive Care Medicine (ESICM)," European Heart Journal, Vol. 29, No. 19, 2008, pp. 2388-2442. http://dx.doi.org/10.1093/eurheartj/ehn309

[4] J. P. Bounhoure, P. Massabuau, M. Galinier, et al., "Heart Failure with Preserved Left Ventricular Function: Clinical, Echocardiographic, and Clinical Course Features. Prognostic Factors," Bulletin of the National Academy of Medicine, Vol. 186, No. 6, 2002, pp. 1013-1014.

[5] R. Nagarakanti and M. Ezekowitz, "Diastolic Dysfunction and Atrial Fibrillation," Journal of Interventional Cardiac Electrophysiology, Vol. 22, No. 2, 2008, pp. 111-118. http://dx.doi.org/10.1007/s10840-008-9203-8

[6] E. J. Benjamin, D. Levy, S. M. Vaziri, et al., "Independent Risk Factors for Atrial Fibrillation in a PopulationBased Cohort. The Framingham Heart Study," JAMA, Vol. 271, No. 11, 1994, pp. 840-844. http://dx.doi.org/10.1001/jama.1994.03510350050036

[7] R. Nieuwlaat, L. W. Eurlings, J. G. Cleland, et al., "Atrial Fibrillation and Heart Failure in Cardiology Practice: Reciprocal Impact and Combined Management from the Perspective of Atrial Fibrillation: Results of the Euro Heart Survey on atrial fibrillation," Journal of the American College of Cardiology, Vol. 53, No. 18, 2009, pp. 1690-1698.

http://dx.doi.org/10.1016/j.jacc.2009.01.055

[8] J. G. Cleland, K. Swedberg, F. Follath, et al., "The EuroHeart Failure Survey Programme-A Survey on the Quality of Care among Patients with Heart Failure in Europe. Part 1: Patient Characteristics and Diagnosis," European Heart Journal, Vol. 24, No. 5, 2003, pp. 442-
463. http://dx.doi.org/10.1016/S0195-668X(02)00823-0

[9] A. J. Camm and I. Savelieva, "Atrial Fibrillation: Advances and Perspectives," Dialogues in Cardiovascular Medicine, Vol. 8, 2003, pp. 183-202.

[10] S. Yusuf, M. A. Pfeffer, K. Swedberg, et al., "Effects of Candesartan in Patients with Chronic Heart Failure and Preserved Left-Ventricular Ejection Fraction: The CHARMPreserved Trial," Lancet, Vol. 362, No. 9386, 2003, pp. 777-781. http://dx.doi.org/10.1016/S0140-6736(03)14285-7

[11] M. Klapholz, M. Maurer, A. M. Lowe, et al., "Hospitalization for Heart Failure in the Presence of a Normal Left Ventricular Ejection Fraction: Results of the New York Heart Failure Registry," Journal of the American College of Cardiology, Vol. 43, No. 8, 2004, pp. 1432-1438. http://dx.doi.org/10.1016/j.jacc.2003.11.040

[12] K. Dickstein, "Natriuretic Peptides in Detection of Heart Failure," Lancet, Vol. 351, No. 9095, 1998, p. 4. http://dx.doi.org/10.1016/S0140-6736(05)78100-9

[13] A. S. Maisel, P. Krishnaswamy, R. M. Nowak, et al., "Rapid Measurement of B-Type Natriuretic Peptide in the Emergency Diagnosis of Heart Failure," The New England Journal of Medicine, Vol. 347, No. 3, 2002, pp. 161167. http://dx.doi.org/10.1056/NEJMoa020233

[14] K. Dickstein, A. Cohen-Solal, G. Filippatos, et al., "ESC Guidelines for the Diagnosis and Treatment of Acute and Chronic Heart Failure 2008: The Task Force for the Diagnosis and Treatment of Acute and Chronic Heart Failure 2008 of the European Society of Cardiology. Developed in collaboration with the Heart Failure Association of the ESC (HFA) and endorsed by the European Society of Intensive Care Medicine (ESICM)," European Journal of Heart Failure, Vol. 10, No. 10, 2008, pp. 933-989. http://dx.doi.org/10.1016/j.ejheart.2008.08.005

[15] P. Verdecchia, G. Schillaci, C. Borgioni, et al., "Prognostic Value of a New Electrocardiographic Method for Diagnosis of Left Ventricular Hypertrophy in Essential Hypertension," Journal of the American College of Cardiology, Vol. 31, No. 2, 1998, pp. 383-390. http://dx.doi.org/10.1016/S0735-1097(97)00493-2

[16] A. S. Go, E. M. Hylek, K. A. Phillips, et al., "Prevalence of Diagnosed Atrial Fibrillation in Adults: National Implications for Rhythm Management and Stroke Prevention: The Anticoagulation and Risk Factors in Atrial Fibrillation (ATRIA) Study," JAMA, Vol. 285, No. 18, 2001, pp. 2370-2375. http://dx.doi.org/10.1001/jama.285.18.2370

[17] D. J. Sahn, A. DeMaria, J. Kisslo, et al., "Recommendations regarding Quantitation in M-Mode Echocardiography: Results of a Survey of Echocardiographic Measurements," Circulation, Vol. 58, No. 6, 1978, pp. 1072-1083. http://dx.doi.org/10.1161/01.CIR.58.6.1072

[18] N. B. Schiller, H. Acquatella, T. A. Ports, et al., "Left Ventricular Volume from Paired Biplane Two-Dimensional Echocardiography," Circulation, Vol. 60, No. 3, 1979, pp. 547-555. http://dx.doi.org/10.1161/01.CIR.60.3.547

[19] R. M. Lang, M. Bierig, R. B. Devereux, et al., "Recommendations for Chamber Quantification: A Report from 
the American Society of Echocardiography's Guidelines and Standards Committee and the Chamber Quantification Writing Group, Developed in Conjunction with the European Association of Echocardiography, a Branch of the European Society of Cardiology," Journal of the American Society of Echocardiography, Vol. 18, No. 12, 2005, pp. 1440-1463.

http://dx.doi.org/10.1016/j.echo.2005.10.005

[20] J. D. F. Cleland, E. Erdmann, R. Ferrari, et al., "Guidelines for the Diagnosis of Heart Failure. The Task Force on Heart Failure of the European Society of Cardiology," European Heart Journal, Vol. 16, No. 6, 1995, pp. 741751.

[21] S. F. Nagueh, C. P. Appleton, T. C. Gillebert, et al., "Recommendations for the Evaluation of Left Ventricular Diastolic Function by Echocardiography," European Journal of Echocardiography, Vol. 10, No. 2, 2009, pp. 165-193. http://dx.doi.org/10.1093/ejechocard/jep007

[22] M. J. Koren, R. B. Devereux, P. N. Casale, et al., "Relation of Left Ventricular Mass and Geometry to Morbidity and Mortality in Uncomplicated Essential Hypertension," Annals of Internal Medicine, Vol. 114, No. 5, 1991, pp. 345-352. http://dx.doi.org/10.7326/0003-4819-114-5-345

[23] B. M. Massie and N. B. Shah, "Evolving Trends in the Epidemiologic Factors of Heart Failure: Rationale for Preventive Strategies and Comprehensive Disease Management," American Heart Journal, Vol. 133, No. 6, 1997, pp. 703-712.

http://dx.doi.org/10.1016/S0002-8703(97)70173-X

[24] F. Ceia, C. Fonseca, T. Mota, et al., "Prevalence of Chronic Heart Failure in Southwestern Europe: The EPICA Study," European Journal of Heart Failure, Vol. 4, No. 4, 2002, pp. 531-539. http://dx.doi.org/10.1016/S1388-9842(02)00034-X

[25] G. F. Mureddu, N. Agabiti, V. Rizzello, et al., "Prevalence of Preclinical and Clinical Heart Failure in the Elderly. A Population-Based Study in Central Italy," European Journal of Heart Failure, Vol. 14, No. 7, 2012, pp. 718-729. http://dx.doi.org/10.1093/eurjhf/hfs052

[26] J. G. Cleland, A. Khand and A. Clark, "The Heart Failure Epidemic: Exactly How Big Is It?" European Heart Journal, Vol. 22, No. 8, 2001, pp. 623-626. http://dx.doi.org/10.1053/euhj.2000.2493

[27] J. Grewal, R. S. McKelvie, H. Persson, et al., "Usefulness of N-Terminal Pro-Brain Natriuretic Peptide and Brain Natriuretic Peptide to Predict Cardiovascular Outcomes in Patients with Heart Failure and Preserved Left Ventricular Ejection Fraction," American Journal of Cardiology, Vol. 102, No. 6, 2008, pp. 73373-73377. http://dx.doi.org/10.1016/j.amjcard.2008.04.048

[28] S. J. Phillips, J. P. Whisnant, W. M. O'Fallon, et al., "Prevalence of Cardiovascular Disease and Diabetes Mel- litus in Residents of Rochester, Minnesota," Mayo Clinic Proceedings, Vol. 65, No. 3, 1990, pp. 344-359. http://dx.doi.org/10.1016/S0025-6196(12)62535-X

[29] F. Bursi, S. A. Weston, M. M. Redfield, et al., "Systolic and Diastolic Heart Failure in the Community," JAMA, Vol. 296, No. 18, 2006, pp. 2209-2216. http://dx.doi.org/10.1001/jama.296.18.2209

[30] N. Ilksoy, M. Hoffman, R. H. Moore, et al., "Comparison of African-American Patients with Systolic Heart Failure versus Preserved Ejection Fraction," American Journal of Cardiology, Vol. 98, No. 6, 2006, pp. 806-808. http://dx.doi.org/10.1016/j.amjcard.2006.03.066

[31] E. P. Havranek, F. A. Masoudi, K. A. Westfall, et al., "Spectrum of Heart Failure in Older Patients: Results from the National Heart Failure Project," American Heart Journal, Vol. 143, No. 3, 2002, pp. 412-417. http://dx.doi.org/10.1067/mhj.2002.120773

[32] J. I. Haft and L. E. Teichholz, "Echocardiographic and clinical risk factors for atrial fibrillation in hypertensive patients with ischemic stroke," American Journal of Cardiology, Vol. 102, No. 10, 2008, pp. 1348-13451. http://dx.doi.org/10.1016/j.amjcard.2008.07.009

[33] F. L. Dini, U. Conti, P. Fontanive, et al., "Prognostic Value of N-Terminal Pro-Type-B Natriuretic Peptide and Doppler Left Ventricular Diastolic Variables in Patients with Chronic Systolic Heart Failure Stabilized by Therapy," American Journal of Cardiology, Vol. 102, No. 4, 2008, pp. 463-468. http://dx.doi.org/10.1016/j.amjcard.2008.03.083

[34] B. Al-Aloul, J. M. Li, D. Benditt, et al., "Atrial fibrillation Associated with hypokalemia due to Primary Hyperaldosteronism (Conn's Syndrome)," Pacing and Clinical Electrophysiology, Vol. 29, No. 11, 2006, pp. 1303-1305. http://dx.doi.org/10.1111/j.1540-8159.2006.00536.x

[35] E. J. Topol, T. A. Traill and N. J. Fortuin, "Hypertensive Hypertrophic Cardiomyopathy of the Elderly," The New England Journal of Medicine, Vol. 312, No. 5, 1985, pp. 277-283. http://dx.doi.org/10.1056/NEJM198501313120504

[36] J. S. Shinbane, M. A. Wood, D. N. Jensen, et al., "Tachycardia-Induced Cardiomyopathy: A Review of Animal Models and Clinical Studies," Journal of the American College of Cardiology, Vol. 29, No. 4, 1997, pp. 709-715. http://dx.doi.org/10.1016/S0735-1097(96)00592-X

[37] M. M. Redfield, G. N. Kay, L. S. Jenkins, et al., "Tachycardia-Related Cardiomyopathy: A Common Cause of Ventricular Dysfunction in Patients with Atrial Fibrillation Referred for Atrioventricular Ablation," Mayo Clinic Proceedings, Vol. 75, No. 8, 2000, pp. 790-795. http://dx.doi.org/10.4065/75.8.790 